\title{
Convective Drying of Sewage Sludge Layer in Through-flow
}

\author{
Andraž Lipolt ${ }^{1}$ - Brane Širok ${ }^{2}$ - Marko Hočevar ${ }^{2}$ - Lovrenc Novak2,* \\ 1 Petrol d.d., Slovenia \\ 2 University of Ljubljana, Faculty of Mechanical Engineering, Slovenia
}

\begin{abstract}
Drying of the sewage sludge layer was investigated in a convective laboratory dryer at air temperatures of $65{ }^{\circ} \mathrm{C}$ and $80{ }^{\circ} \mathrm{C}$ and air speeds of $0.53 \mathrm{~m} / \mathrm{s}$ and $0.83 \mathrm{~m} / \mathrm{s}$. The sludge layer was formed by loading cylindrical extrudates on a grate of $0.5 \mathrm{~m} \times 0.5 \mathrm{~m}$ size. The drying air was directed through the layer, as typically encountered in industrial belt dryers. Under such setup, the sludge layer structure and porosity significantly affect the air flow conditions and thus the drying rates. Shrinkage and cracking of the material during drying caused changes in the layer's porous structure, that affected the pressure drop and the drag force due to passing of air through the layer. The decreasing of drag force over time was modeled by a simple function that showed excellent agreement to the selected measured data. The sludge layer drying kinetics was determined by fitting the measured data to the most common drying models. Two models, the modified Nadhari and the Wang Singh model, were determined as most suitable for modeling of drying curves. The total drying time per kilogram of sludge was modeled as a function of drying air temperature, drying air velocity and initial sludge dry matter content. The coefficient of determination $\left(R^{2}\right)$ of the model is 0.944. Total drying times between 43 minutes per kilogram and 76 minutes per kilogram of sludge were obtained for the investigated range of drying air conditions.
\end{abstract}

Keywords: wastewater sludge, thin-layer drying, porous layer, drying kinetics, drag force

Highlights

- The sewage sludge drying experiments were conduced by blowing hot air through the porous sludge layer of $0.25 \mathrm{~m}^{2}$ area.

- The through-flow setup enabled representation of conditions in belt dryers and capturing of the effects of time-varying layer porosity.

- The modified Nadhari and the Wang Singh model were determined as most suitable for modeling of drying curves.

- The drag force due to passing of air through the layer was modeled by a simple decreasing function.

- The total drying time per kilogram of sludge was modeled as a function of the sludge dry matter content and the drying air conditions.

\section{INTRODUCTION}

The sludge generated in the wastewater treatment process is a very complex material with many of its properties depending on the wastewater characteristics and on the treatment technology. Wastewater characteristics vary by source, which can be any combination of domestic, municipal, also known as sewage, and industrial activities. Wastewater may contain physical, chemical and biological contaminants, therefore handling and disposal of sludge is of great concern. The most widely available options for sludge end-use in the EU are the agriculture utilization, the waste disposal sites, the land reclamation and restoration, the incineration and other novel uses [1]. Legal limitations concerning landfilling and agricultural reuse due to contaminants are increasing the role of sludge incineration in combination with recovery of nutrients, especially phosphorus [2] and [3].

The sludge produced by wastewater treatment plants must generally be dehydrated before incineration, as it contains a high percentage of water. By using mechanical water extraction, it is typically possible to achieve sludge solid content up to $30 \mathrm{wt} \%$. Further reduction of water content can be achieved by drying. Typical sludge drying methods used in the industry are convective drying, conductive drying and solar drying [4]. The most common method is convective drying; compared to conductive drying it generally involves a simpler design of the drying system and shorter drying times [5]. The convective drying systems are based on belt dryers, flash dryers, fluidized bed dryers and rotary dryers. The present study is focused on convective drying with specifics that are relevant to conditions in belt dryers. Fundamental aspects of sludge drying by the convective process have been examined by several authors. They presented the influential parameters of convective drying and concluded that the drying air temperature, its velocity and humidity are the most important parameters that affect the drying rates [6]. Sludge composition has also been found to influence experimental results [7], which indicates the need to study drying behavior for sludges of different characteristics. Determination of optimum drying conditions prior to drying can improve energy efficiency of the process and avoid problems such as 
inhomogeneously dried material with the formation of a skin [8] and [9].

Most reported sludge drying studies are performed on small sludge samples with masses of a few grams in form of single cylindrical extrudates, balls or cakes [6] to [15]. Some studies also deal with larger sludge samples in form of a porous bed [16] to [20]. Study [5] compared drying of a small sludge sample $(2.5 \mathrm{~g})$ and sludge bed $(250 \mathrm{~g})$ and found significant differences between the two drying processes. Drying of sludge bed exhibited three typical drying phases: the adaptation phase, the constant drying rate phase and the falling drying rate phase, while no constant rate drying phase was detected during the drying of small sample. Size of sample has further implications on the drying process as some effects become evident only when drying larger quantities of sludge, typically in shape of porous layers. The layer characteristics and its transformation during drying, mainly due to shrinkage and cracking, influence the drying process. Moreover, in case of drying air being forced through the porous sludge layer, as typically encountered in industrial large-scale belt dryers, these effects are even more significant. Several researchers investigated the influence of sludge structural characteristics on heat and mass transfer phenomena [10], [14], and [19] to [22], with emphasis on changes in porous structure that are caused by shrinking and cracking of the material. Relationships between the sludge structure and the functional characteristics of drying, such as the energy efficiency of sludge drying, were presented.

In most cases, the sludge obtained after the initial mechanical water removal processes is a soft, pasty and sticky wet material that is difficult to handle and dry. Due to the low stiffness of the resulting porous sludge structure, the layer deforms, which results in the reduction of free pores in the sludge and, consequently, the reduction of the transfer surface on which convective transfer of heat and water vapor takes place. The phenomenon was discussed by the authors in study [22], where adding of dry matter (sawdust) increased the stiffness of a porous substance on a laboratory scale, resulted in shorter drying times and higher energy efficiency of the process. However, it should be emphasized that technologies with the introduction of secondary raw materials such as sawdust [17] to [19] and [22] or pulverized coal [23] and [24] are associated with economic limitations arising from the costs of these materials and requirements for increased capacity of drying facilities.

The aim of this work is to analyze the sewage sludge drying, where sludge is shaped as a porous layer and the drying air is blown through the layer.
For this purpose, experiments were conducted on a laboratory drying facility, where sludge samples of several kilograms were dried in a layer of $0.5 \mathrm{~m} \times$ $0.5 \mathrm{~m}$ size. The selected sample size enabled effects related to time-varying characteristics of the porous layer to manifest in large scale and thus affect the drying process. Contrary to most reported research, current study involved airflow being forced through the sludge layer. Under such setup the layer porosity on both local and integral scale significantly affects the air flow paths and thus the drying rates. The analysis of measured results was focused at evaluation of drying kinetics and at development of models for description of the sludge drying process at integral level. Since conditions in the presented study are closely related to the industrial belt dryers, the presented results could be scaled-up and applied to real large-scale dryers.

\section{MATERIALS AND METHODS}

\subsection{Experimental Setup}

The sludge drying experiments were performed on a laboratory scale convective drying system as shown in Fig. 1. The central part of the system is the drying chamber with perforated grate, which holds the porous sludge layer. The grate area is $0.25 \mathrm{~m}^{2}$ and covers the entire chamber cross section. The circulation of air through the chamber is provided by a circulating fan located outside the drying chamber. The circulating drying air enters the drying chamber at the top, passes through the sludge layer and is extracted out of the chamber at the bottom. To maintain the desired drying air temperature, an electric heater is installed in the circulating air system. The heater has a nominal electrical power of $2 \mathrm{~kW}$ and is controlled by a temperature regulator. The extraction fan at the top of the chamber is used for partial extraction of moist air from the system and thus for supply of fresh air into the chamber. By adjusting the extraction flow, the relative humidity of the drying air in the chamber is controlled. Both the circulating and the extraction fan are controlled by variable frequency drives. By independently adjusting the circulating and extraction fan speeds and by controlling the heater, a wide range of drying air parameters above the layer can be achieved: air velocity up to $1 \mathrm{~m} / \mathrm{s}$, air temperature up to $90{ }^{\circ} \mathrm{C}$ (limited by the sludge weighing system) and air relative humidity up to $90 \%$ (lower limit depends on ambient conditions and other parameters of the drying air). 


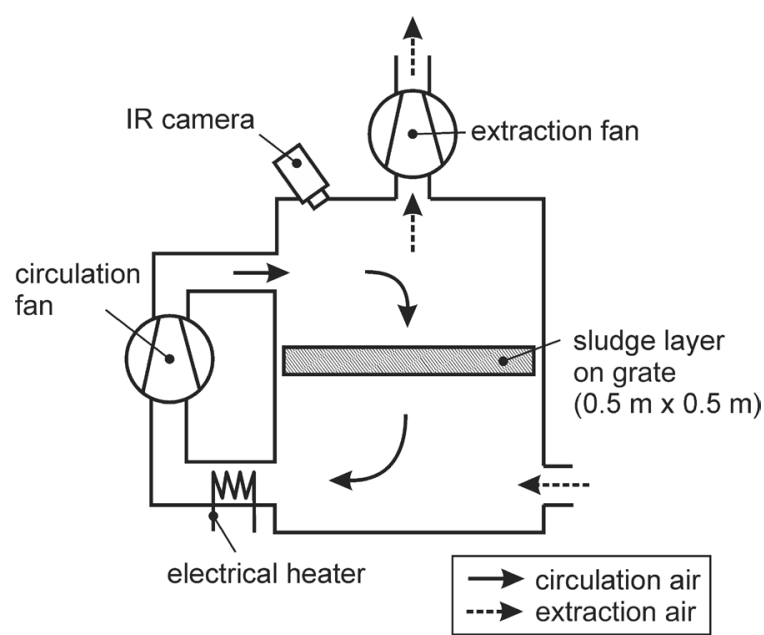

Fig. 1. Laboratory convective dryer

The convective dryer is equipped with a measurement system for monitoring of process variables, including the air and the sludge temperatures, the air relative humidity, the air static pressure, the air flow rate and the sludge mass. All temperatures were measured by the Pt100 resistive temperature detectors (RTD), accuracy class A. The air relative humidity $(\mathrm{RH})$ was measured by the calibrated Honeywell HIH-4000 hygrometers $( \pm 3.5 \%$ $\mathrm{RH}$ accuracy). The air static pressures were measured by the Endress+Hauser Deltabar PMD235 differential pressure transducers $( \pm 0.1 \%$ accuracy $)$. The drying air conditions were measured above the sludge layer (4 RTDs), below the sludge layer (4 RTDs) and in the extraction pipe at the top of the drying chamber (1 RTD and 1 hygrometer). Additionally, the ambient air conditions at the chamber inlet were also measured (1 RTD and 1 hygrometer). Downstream of the extraction fan an orifice plate was installed into the pipe to enable determination of the extracted air flow rate. The orifice plate and the pressure taps were manufactured according to the ISO standard [28] and connected to a differential pressure transducer. Air temperature was also measured at the orifice plate (1 RTD) to enable the air density determination and calculation of volume flow rate (accuracy \pm 3 $\%$ ). Static pressure difference between the top and the bottom section of the drying chamber (pressure drop across the sludge and grate) was measured by a differential pressure transducer, connected to pressure taps at the chamber walls. The sludge condition was monitored by measuring its temperature and mass. The sludge surface temperature was measured by the FLIR T425 infra-red camera. The camera was mounted at the top of the drying chamber, where a
ZnSe window was installed to enable observation of the sludge in IR spectrum. Online weighing of sludge mass was performed by a high temperature load cell Pavone Systems C2G1 HT with $20 \mathrm{~kg}$ capacity (combined error $\pm 0.02 \%$ of full scale output), which was installed into the drying chamber below the grate. Weighing of the sludge before and after drying was additionally performed on a Kern FKB $15 \mathrm{~K} 0.5 \mathrm{~A}$ scale with linearity of $1.5 \mathrm{~g}$. All sensors were connected to the Agilent 34970A data acquisition (DAQ) unit and were sampled in 20-second intervals over the entire drying time. Measured data was monitored and saved for further analysis by using the Benchlink Data Logger software running on a PC. The DAQ unit features high accuracy: $\pm(0.004 \%$ reading + $0.004 \%$ range) for $\mathrm{DC}$ voltage at $100 \mathrm{mV}$ range and $\pm(0.002 \%$ reading $+0.0007 \%$ range $)$ for $\mathrm{DC}$ voltage at $10 \mathrm{~V}$ range. Its contribution to combined measurement uncertainty in all measured variables is very low or insignificant. Nevertheless, it was included for calculation of the combined measurement uncertainty for online sludge weighing. According to the uncertainty propagation laws the sludge mass weighing uncertainty was calculated to be $\pm 5.7 \mathrm{~g}$.

The drying air velocity was not measured directly but was calculated from the volume flow rate, which was determined on the basis of the fan performance curve, the measured pressure drop, the temperature and the relative humidity of the drying air. Additionally, the layer pressure drop vs. air velocity characteristic was determined prior to experiments. For this purpose, the layer pressure drop was varied by placing mats of different porosity on the grate. For each pressure drop, the air velocity was measured by a hot-film probe at 12 points just above the layer. The pressure drop was plotted as a function of the area-weighted average air velocity to obtain the layer resistance curve, which was then used for determination of the air velocity from the measured pressure drop. It has to be noted, that the layer pressure drop represented a minor part of the total pressure drop across the air circulation system, therefore its variation had little influence on the fan performance and consequently the air velocity. Based on the typical fan performance curve measurement uncertainty and the presented layer resistance curve measurement method it is estimated that the air velocity was determined at $\pm 5 \%$ accuracy.

\subsection{Experimental Procedure}

The sewage sludge used in the experiments was obtained from the sewage sludge belt dryer located in Ihan, Slovenia. The sludge was essentially a mixture 
of sludges from different municipal wastewater treatment plants in Slovenia. The sludge was collected at the outlet of the die press system, which generates extrudates of approximately $10 \mathrm{~mm}$ diameter. The extruded sludge was daily delivered to the location of the laboratory dryer in a sealed container in amounts that were sufficient for 2 drying tests. The initial moisture content of the sludge was determined from samples taken before each drying experiment and was on average $4.24 \mathrm{~kg}$ (water) per kg (dry matter) or $80.9 \%$ water. The moisture content was determined by complete evaporation of water from the samples at $90{ }^{\circ} \mathrm{C}$. The same method was employed to determine the final moisture content of sludge samples that were taken at the end of each drying test.

Before each drying test, the grate was removed from the drying chamber and the laboratory dryer was preheated to the selected temperature level. The sludge was applied to the grate manually, where special attention was given to an even distribution of extrudates and generation of an uniform layer. The initial sludge layer mass was $4.8 \mathrm{~kg}$ on average but could vary by as much as $\pm 0.6 \mathrm{~kg}$ from test to test. The initial sludge layer thickness was approximately $40 \pm 5 \mathrm{~mm}$. The extrudate length after formation of the layer was approximately $50 \mathrm{~mm}$, however, during manipulation some formation of larger sludge aggregates could not be avoided due to the soft and sticky nature of the material. Placement of extrudates was predominantly parallel to the grate (horizontal) with random orientation. The prepared sludge layer was weighed on the laboratory scale and then inserted into the heated dryer. During drying, the circulation fan was periodically stopped for up to 30 seconds in order to eliminate the drag force from the weighed data according to the procedure, explained later in Eq. (1). The drying process was performed until no significant sludge mass variation could be detected. Then the grate with the dried sludge was removed from the dryer and again weighed on the laboratory scale.

The experiment was carried out at different drying air conditions (temperature, velocity, relative humidity) to determine their effect on drying kinetics. Two levels were selected for each of the stated variables by considering the operating conditions, present in the full-scale convective dryer in Ihan, Slovenia. The low and high temperature level were selected to be $65{ }^{\circ} \mathrm{C}$ and $80{ }^{\circ} \mathrm{C}$, respectively, and were maintained during drying by the temperature regulator. The high air velocity level was selected as the maximum possible (full fan speed) and was later determined to be on average $0.83 \mathrm{~m} / \mathrm{s}$, while the low velocity level was selected by setting the fan rotational speed to $60 \%$, which corresponded to $0.53 \mathrm{~m} / \mathrm{s}$ air velocity. The relative humidity $(\mathrm{RH})$ of the drying air was not regulated during drying but instead two levels of fixed air extraction rates were selected. Under the low and high extraction rates, the average relative humidity of the air above the sludge layer was $20 \%$ to $30 \%$ and $40 \%$ to $60 \%$, respectively.

Table 1. Definition of operating conditions

\begin{tabular}{lcccc}
\hline Test & $v[\mathrm{~m} / \mathrm{s}]$ & $T$ [ $\left.^{\circ} \mathrm{C}\right]$ & $V_{\text {ex }}$ & $R H_{\text {ave }}[\%]$ \\
\hline 1-HHH & 0.82 & 80 & high & 22 \\
\hline 2-HHL & 0.82 & 80 & low & 35 \\
\hline 3-HLH* & 0.84 & 65 & high & 32 \\
\hline 4-HLL & 0.84 & 65 & low & 60 \\
\hline 5-LLL* & 0.53 & 65 & low & 39 \\
\hline 6-LLH & 0.53 & 65 & high & 31 \\
\hline 7-LHH & 0.53 & 80 & high & 21 \\
\hline 8-LHL & 0.53 & 80 & low & 39 \\
\hline
\end{tabular}

*complete drying curve not available from measured data

In total 8 drying tests were required to cover all possible combinations of the selected process variable levels. In fact, more tests were performed, however, some had to be rejected due to incomplete or invalid data. After final analysis, 6 tests were identified to provide complete drying kinetics data and 2 additional tests were identified to provide limited data, sufficient only for the analysis of the total drying time. Further repetition of tests was not possible due to interruption in operation of the dryer in Ihan and consequent variability in supplied sludge properties. An overview of the performed tests is given in Table 1. Each test was given a designation consisting of a sequential number and a sequence of letters, indicating the set level for air velocity $(v)$, temperature $(T)$ and extraction rate $\left(V_{e x}\right)$, where $\mathrm{H}$ and $\mathrm{L}$ indicate high and low level, respectively.

It is evident from Table 1 that all possible combinations of the chosen process variables were measured, however, sludge mass data for 2 tests (3HLH and 5-LLL) was insufficient for a complete drying kinetics analysis. It also has to be noted that the method of controlling the drying air RH by setting fixed air extraction rates was quite rough and could not maintain fixed $\mathrm{RH}$ levels or provide equal $\mathrm{RH}$ differences between the tests.

\subsection{Processing of Measured Data}

The weighing data from the load cell in general included gravity forces due to the mass of sludge, the 
mass of steel grate and the drag force due to passing of drying air through the porous sludge layer. After subtracting the mass of steel grate from the weighed data, the data still contained contributions from both the sludge mass and the drag force. The drag force was eliminated periodically by stopping the circulation fan for up to 30 seconds. The corresponding weighing at zero air flow provided the actual sludge mass. The drag force was calculated by subtracting the actual sludge mass from the weighed mass, obtained as soon as the circulation fan was back in normal operation. The delay between the actual sludge mass determination and the drag force calculation was typically 40 seconds, which corresponds to 2 data samples.

$$
m_{\text {drag }, i}=m_{w e, i+2}-m_{s l, i},
$$

where $m_{\text {drag }, i}$ is the drag force (expressed as mass), $m_{w e}$ is the total weighed mass (without grate mass), $m_{s l}$ is the sludge mass and $i$ is the data sample number.

The drying curves typically display either the moisture content $(X)$ or the moisture ratio $(M R)$ as a function of time. The moisture content is defined as the mass of water per mass of dry matter and was calculated according to Eq. (2).

$$
X=\frac{m_{w}}{m_{d m}}=\frac{m_{s l}-m_{d m}}{m_{d m}},
$$

where $m_{w}$ is the water mass, $m_{s l}$ is the sludge mass and $m_{d m}$ is the sludge dry matter. The dry matter was determined from sludge samples, taken before each drying test, by complete evaporation of water from the sample. The dimensionless moisture ratio can be calculated using the equation $M R=\left(X_{t}-X_{e}\right) /\left(X_{0}-X_{e}\right)$. The equilibrium moisture content, $X_{e}$, is often assumed to be zero, which simplifies the moisture ratio definition to [29]:

$$
M R=\frac{X}{X_{0}},
$$

where $X$ is the moisture content at given time and $X_{0}$ the initial moisture content.

\subsection{Mathematical Modeling of Drying Curves}

The sludge mass as a function of time represents the fundamental characteristic of the drying process and is referred to as the drying curve. Characterization of drying kinetics typically involves modeling of drying curves by fitting measured values to various theoretical, semi-theoretical and empirical drying laws. Researchers [27] identified 67 different drying curve equations of various complexity for modeling of thin-layer drying, however, only 2 out of 390 reviewed references were dealing with sludge drying. Generally, modeling of sewage sludge convective drying by semi-theoretical or empirical equations has been attempted by several researchers [10], [15], [19], [21], [24] and [28] to [31]. Studies demonstrated various models as the most appropriate for description of the drying curves, most probably due to the fact that sewage sludge composition and properties (hence drying kinetics) are highly variable. Furthermore, drying experiments were performed in different setups and under a wide range of conditions, which also affects the drying kinetics.

Table 2. Used drying models

\begin{tabular}{llc}
\hline Model name & Model equation & Parameters \\
\hline Newton [32] & $M R=\exp (-k \cdot t)$ & $k$ \\
\hline Page [33] & $M R=\exp \left(-k \cdot t^{n}\right)$ & $k, n$ \\
\hline Wang-Singh [34] & $M R=1+a \cdot t+b \cdot t^{2}$ & $a, b$ \\
\hline Logarithmic [35] & $M R=a \exp (-k \cdot t)+b$ & $a, k, b$ \\
\hline Midilli [26] & $M R=a \exp \left(-k \cdot t^{n}\right)+b \cdot t$ & $a, k, n, b$ \\
\hline Mod. Midilli & $M R=\exp \left(-k \cdot t^{n}\right)+b \cdot t$ & $k, n, b$ \\
\hline Two-term [36] & $M R=a \exp (-k \cdot t)+b \exp (-n \cdot t)$ & $a, k, b, n$ \\
\hline Nadhari [37] & $M R=a \exp \left(-k \cdot t^{n}\right)+b$ & $a, k, n, b$ \\
\hline Modified Nadhari & $M R=a \exp \left(-k \cdot t^{n}\right)+(1-a)$ & $a, k, n$ \\
\hline
\end{tabular}

In the present study, drying curves were modeled by fitting measured data (moisture ratio versus time) to the most important semi-theoretical and empirical models (Table 2) that are widely used in the scientific literature to describe the kinetics of the drying process [27] and [38]. The original Midilli [26] and Nadhari [37] models were modified by considering the initial condition of $M R=1$ at $t=0$, which made one parameter in both of the models into constant, thus reducing the parameter count from 4 to 3 . This simplification caused an insignificant reduction of the models' predictive power while making them more comparable to the other models that include 3 or less parameters.

Regression analysis was used to obtain the parameters in each of the selected models. The analysis was performed in MS Excel by using the GRG nonlinear solver to minimize the sum of squared errors. The coefficient of determination $\left(R^{2}\right)$, reduced chi-square $\left(\chi^{2}\right)$ and the root mean square error (RMSE) were calculated for each model in order to test their accuracy in reproducing the experimental data. The higher values of the coefficient of determination and the lower values of the reduced chi-square and $R M S E$ 
were chosen for goodness of fit [38]. These parameters were calculated as:

$$
\begin{gathered}
R^{2}=1-\frac{\sum_{i=1}^{N}\left(M R_{\text {exp }, i}-M R_{\text {pre }, i}\right)^{2}}{\sum_{i=1}^{N}\left(M R_{\text {exp }, i}-M R_{\text {exp }, \text { ave }}\right)^{2}}, \\
\chi^{2}=\frac{\sum_{i=1}^{N}\left(M R_{\text {exp }, i}-M R_{\text {pre }, i}\right)^{2}}{N-n}, \\
R M S E=\left[\frac{1}{N} \sum_{i=1}^{N}\left(M R_{\text {exp }, i}-M R_{p r e, i}\right)^{2}\right]^{1 / 2},
\end{gathered}
$$

where $M R_{\text {exp, } i}$ is the experimental moisture ratio, $M R_{\text {pre }, i}$ the predicted moisture ratio, $M R_{\text {exp,ave }}$ the average experimental moisture ratio, $N$ the number of data points and $n$ the number of constants in the regression model.

\section{RESULTS AND DISCUSSION}

\subsection{Modeling of Drying Curves}

The most significant measured quantities for a selected representative operating condition (8LHL) are presented in Fig. 2. Thermal conditions are represented by the measured temperatures of the air below and above the sludge layer and by the calculated temperature difference across the layer (" $d T$ layer" curve). The displayed air temperatures are in fact average values calculated from readings of 4 RTDs above and below the layer, respectively. The temperature of drying air was set to $80{ }^{\circ} \mathrm{C}$ in the presented operating condition, however, it is evident that the initial air temperature was actually around $70{ }^{\circ} \mathrm{C}$ and reached the set value only after
60 minutes. The length of the air warming-up stage was a function of the maximum heater power and the operating conditions, primarily the set temperature. In operating conditions with lower set temperature $\left(65^{\circ} \mathrm{C}\right)$, the warming-up stage typically involved a starting temperature of $60{ }^{\circ} \mathrm{C}$ and lasted less than 20 minutes. Generally, the temperature difference across the layer was not affected by the initial air warmingup stage and instead showed a shorter transient period, lasting approximately 15 minutes. This period is characterized by the highest temperature differences and by fast increasing of the drying air relative humidity and reflects the initial sludge warmingup stage. From here on, the temperature difference is decreasing with an almost steady gradient which signifies the falling drying rate period.

At around 135 minutes the falling rate of temperature and RH (" $d T$ layer" and " $R H$ extraction" in Fig. 2a) is slightly increased, which could indicate a change in drying rate. However, such evident change in falling rate was not typical for other operating conditions. In contrast, the variation of pressure drop across the sludge layer ( $d p$ layer) as presented in Fig. 2b was typical for all operating conditions. The pressure drop decreased continuously with time. The highest pressure drop gradient and hence most pressure drop reduction occurred during the first half of drying. In the second half of drying the pressure drop gradually stabilized at an almost constant value. Periodical pressure drops of $0 \mathrm{~Pa}$ reflect stopping of the circulation fan for the purpose of sludge weighing.

More details on the weighed sludge mass for the selected operating condition 8-LHL are given in Fig. 3. The actual sludge mass was recorded only when the circulation fan was stopped and consequently the drag force was eliminated. In the presented
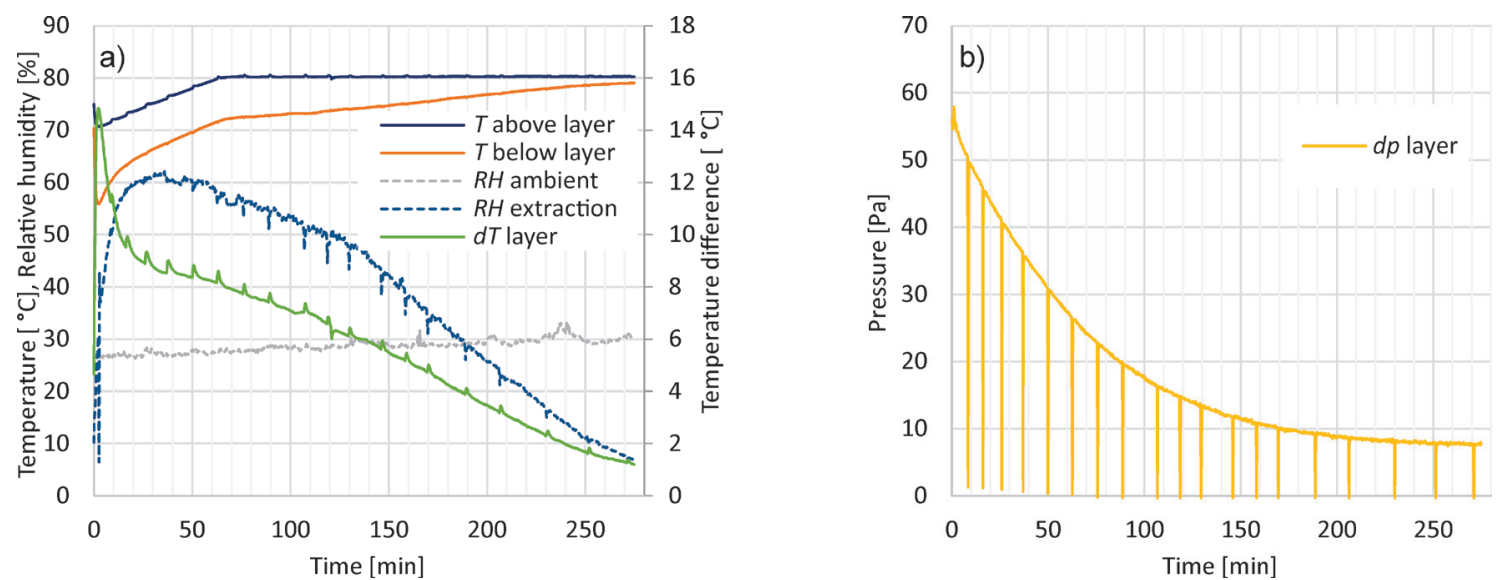

Fig. 2. Measured quantities for a representative operating condition; a) temperatures and relative humidities, and b) pressure drop 


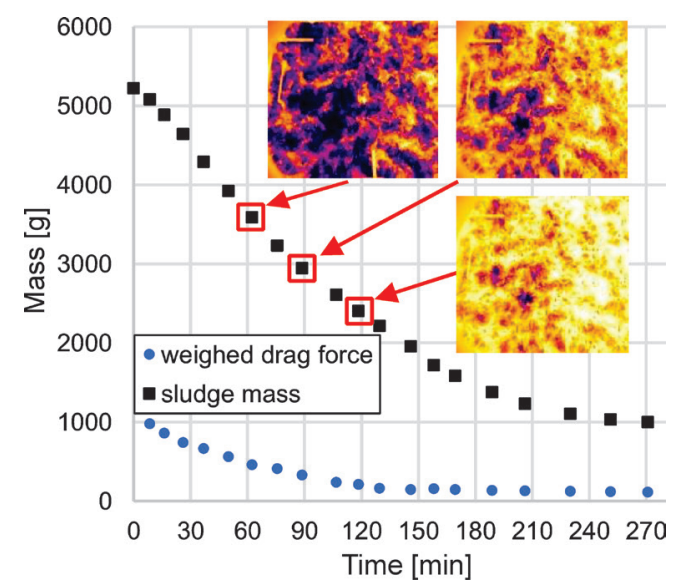

Fig. 3. Weighed masses and sludge surface thermograms for operating condition 8-LHL

operating condition, there were 19 instances of fan stopping for the purpose of weighing. The point at $t=0$ corresponds to sludge weighing before drying and represents an additional sludge mass value. The drag force was determined by subtracting the sludge mass from the weighed total mass at normal fan operation (Eq. (1)). Fig. 3 also displays 3 thermograms of the sludge surface, taken at 3 different sludge weighing instances. The thermograms were used as an indication of the evenness of the drying rates across the sludge layer. Evenness or uniformity of drying is ensured by an uniform airflow through the sludge layer, which mostly depends on the layer structure and porosity distribution. High drying uniformity is desired as it is associated with higher drying efficiency, lower drying times and uniformly dried end-product. In the presented research, uniformity of sludge layer structure was monitored and assessed from the recorded thermograms as satisfactory, however, a more detailed analysis and objective quantification of these effects will be performed in scope of future research.

The operating conditions with the most instances of fan stopping and hence the most measured values of actual sludge mass (4-HHL, 8-LHL) were expected to provide the definition of the best drying model equation. However, statistical criteria (RMSE, $R^{2}$, $\left.\chi^{2}\right)$ led to selection of a different equation for each operating condition. In the case of operating condition 4-HHL the best fit was obtained by the Wang-Singh model while in the case of operating condition 8-LHL the best fit was obtained by the modified Nadhari model. Summary of parameters related to fitting the two selected operating conditions is given in Table 3. All remaining measured operating conditions with less frequent sludge weighing were then fitted to the same models. The best fit of data as indicated by the statistical parameters was again obtained either for the Wang Singh or the Nadhari model, as evident in Table 4. In general, tests with higher drying rates were better modeled by the Nadhari model while tests with lower drying rates (drying at lower temperatures and flow rates) by the Wang Singh model, with the exception of operating condition 8-LHL, which was also better modeled by the Nadhari model. The modified Midilli model was statistically always very close to the modified Nadhari model, therefore its parameters were included in Table 4.

Table 3. Parameters and statistics for drying models fitted to tests 4-HLL and 8-LHL

\begin{tabular}{|c|c|c|c|c|c|c|c|c|}
\hline & Model param. & Newton & Page & Wang Singh & Logarithmic & $\begin{array}{l}\text { Modified } \\
\text { Midilli }\end{array}$ & Two-term & $\begin{array}{c}\text { Modified } \\
\text { Nadhari }\end{array}$ \\
\hline \multirow{7}{*}{ 4-HLL } & $a$ & - & - & -0.00745 & 1.27274 & - & -14.024 & 1.1399 \\
\hline & $b$ & - & - & $1.403 \mathrm{E}-05$ & 0.006785 & 0.004348 & 15.04186 & - \\
\hline & $k$ & 0.009982 & 0.002569 & - & -0.25278 & 1.144849 & 0.00399 & 0.0043 \\
\hline & $n$ & - & 1.290009 & - & - & -0.00039 & 0.004282 & 1.1239 \\
\hline & $R M S E$ & 0.04549 & 0.01688 & 0.00291 & 0.00846 & 0.00516 & 0.00719 & 0.00461 \\
\hline & $R^{2}$ & 0.9787 & 0.9971 & 0.9999 & 0.9993 & 0.9997 & 0.9995 & 0.9998 \\
\hline & $\chi^{2}$ & $2.18 \mathrm{E}-03$ & $3.18 \mathrm{E}-04$ & $9.46 \mathrm{E}-06$ & $8.49 \mathrm{E}-05$ & 3.17E-05 & $6.54 \mathrm{E}-05$ & $2.53 \mathrm{E}-05$ \\
\hline \multirow{7}{*}{ 8-LHL } & $a$ & - & - & -0.00688 & 1.278724 & - & 1.127077 & 1.0696 \\
\hline & $b$ & - & - & $1.169 \mathrm{E}-05$ & 0.007368 & 0.002077 & -0.14182 & - \\
\hline & $k$ & 0.009215 & 0.001293 & - & -0.19177 & 1.304418 & 0.010671 & 0.0023 \\
\hline & $n$ & - & 1.415025 & - & - & -0.00016 & 1.210392 & 1.2720 \\
\hline & RMSE & 0.05692 & 0.01533 & 0.01694 & 0.01726 & 0.00817 & 0.03896 & 0.00713 \\
\hline & $R^{2}$ & 0.9724 & 0.9980 & 0.9976 & 0.9975 & 0.9994 & 0.9871 & 0.9994 \\
\hline & $\chi^{2}$ & $3.42 \mathrm{E}-03$ & 2.63E-04 & $3.21 \mathrm{E}-04$ & $3.54 \mathrm{E}-04$ & 7.92E-05 & $1.70 \mathrm{E}-03$ & $8.09 \mathrm{E}-05$ \\
\hline
\end{tabular}


Table 4. Parameters and statistics for drying models fitted to tests that are not included in Table 3

\begin{tabular}{|c|c|c|c|c|}
\hline & Param. & Wang Singh & $\begin{array}{c}\text { Modified } \\
\text { Midillli }\end{array}$ & $\begin{array}{l}\text { Modified } \\
\text { Nadhari }\end{array}$ \\
\hline \multirow{7}{*}{$1-\mathrm{HHH}$} & $a$ & -0.01087 & - & 1.0099 \\
\hline & $b$ & $2.899 \mathrm{E}-05$ & 0.002483 & - \\
\hline & $k$ & - & 1.405839 & 0.0026 \\
\hline & $n$ & - & $-3.91 \mathrm{E}-05$ & 1.3967 \\
\hline & $R M S E$ & 0.01745 & 0.00442 & 0.00417 \\
\hline & $R^{2}$ & 0.99785 & 0.99986 & 0.99988 \\
\hline & $\chi^{2}$ & $4.26 \mathrm{E}-04$ & $3.42 \mathrm{E}-05$ & $3.04 \mathrm{E}-05$ \\
\hline \multirow{7}{*}{ 2-HHL } & $a$ & -0.01043 & - & 0.9978 \\
\hline & $b$ & $2.718 \mathrm{E}-05$ & 0.001389 & - \\
\hline & $k$ & - & 1.555674 & 0.0014 \\
\hline & $n$ & - & $7.3 \mathrm{E}-06$ & 1.5611 \\
\hline & $R M S E$ & 0.02817 & 0.00729 & 0.00725 \\
\hline & $R^{2}$ & 0.9956 & 0.99971 & 0.99971 \\
\hline & $\chi^{2}$ & $1.11 \mathrm{E}-03$ & $9.29 \mathrm{E}-05$ & $9.20 \mathrm{E}-05$ \\
\hline \multirow{7}{*}{ 6-LLH } & $a$ & -0.00686 & - & 1.0767 \\
\hline & $b$ & $1.213 \mathrm{E}-05$ & 0.003927 & - \\
\hline & $k$ & - & 1.153867 & 0.0040 \\
\hline & $n$ & - & -0.00019 & 1.1346 \\
\hline & $R M S E$ & 0.00374 & 0.00434 & 0.00396 \\
\hline & $R^{2}$ & 0.99989 & 0.99986 & 0.99988 \\
\hline & $\chi^{2}$ & $2.10 \mathrm{E}-05$ & $3.76 \mathrm{E}-05$ & $3.14 \mathrm{E}-05$ \\
\hline \multirow{7}{*}{ 7-LHH } & $a$ & -0.00751 & - & 1.0443 \\
\hline & $b$ & 1.447E-05 & 0.003548 & - \\
\hline & $k$ & - & 1.208275 & 0.0036 \\
\hline & $n$ & - & -0.00013 & 1.1940 \\
\hline & $R M S E$ & 0.00407 & 0.00617 & 0.00575 \\
\hline & $R^{2}$ & 0.99989 & 0.99976 & 0.99979 \\
\hline & $\chi^{2}$ & $2.76 \mathrm{E}-05$ & $9.50 \mathrm{E}-05$ & $8.28 \mathrm{E}-05$ \\
\hline
\end{tabular}

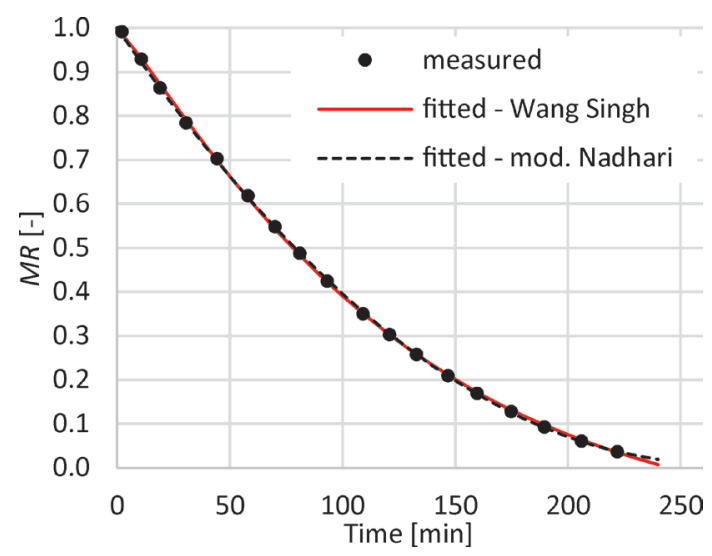

Fig. 4. Weighed and fitted moisture ratio for operating condition 4-HLL

Figs. 4 and 5 show measured and fitted moisture ratios for operating conditions 4-HLL and 8-LHL, respectively. The measured conditons include weighed sludge mass before, during and after drying. Both the Wang Singh and the modified Nadhari models are plotted.

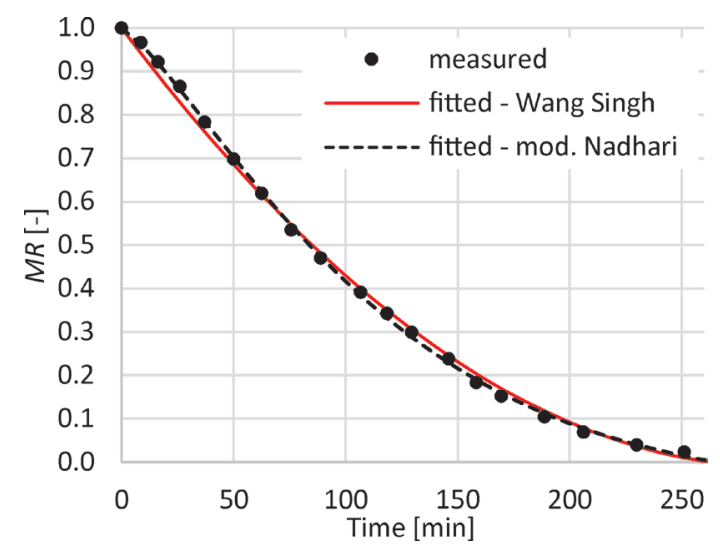

Fig. 5. Weighed and fitted moisture ratio for operating condition 8-LHL

In the case of operating condition 4-HLL both models produce very similar drying curves while in the case of operating condition 8-LHL, differences between the models are more evident. In the latter case the drying curve takes a different shape with initial adaptation stage clearly visible. Both models show some weaknesses at the end of drying, where they could predict negative drying rates (Nadhari) or change from falling to rising drying rates (going past the minimum of the Wang Singh curve, which is a parabola).

Fig. 6 presents modeled moisture ratio for all operating conditions. The best model according to the statistical parameters (Tables 3 and 4) was selected for each operating condition. In total, 3 operating conditions were best fitted by the Wang Singh model and 3 by the modified Nahdari model. It is evident that combining high temperature and high air velocity resulted in significantly higher drying rates with drying kinetics, best described by the modified Nadhari model. Other combinations of velocity and temperature resulted in similar drying curves, that were mostly fitted by the Wang Singh model. Similar observations can be made on the basis of Krischer curves (Fig. 7) that present the drying rate as a function of moisture content. The initial drying rates (curves at the right-hand side of the diagram) are similar for all operating conditions, however, the curve shapes differ significantly. Operating conditions that were modeled by the Wang Singh model clearly show a continuously falling drying rate for the whole range of moisture rates. On the contrary, operating conditions that were 
best modeled by the modified Nadhari model exhibit a significant adaptation stage with rising drying rates that eventually level off and start to fall as the sludge gets dryer. The different drying behaviors, as reflected by the two types of drying curves, could be explained by the limiting mechanism for moisture evaporation. Léonard et al. [6] dried two sludges of different origin and concluded that the drying curve without adaptation phase reflects the presence of internal (diffusional) limitations from the beginning of drying, while the more typical drying curve reflects control of drying by external (sludge to air) limitations. It has to be noted though, that this explanation can not be proven in relation to the presented work and therefore has to be treated as hypothetical.

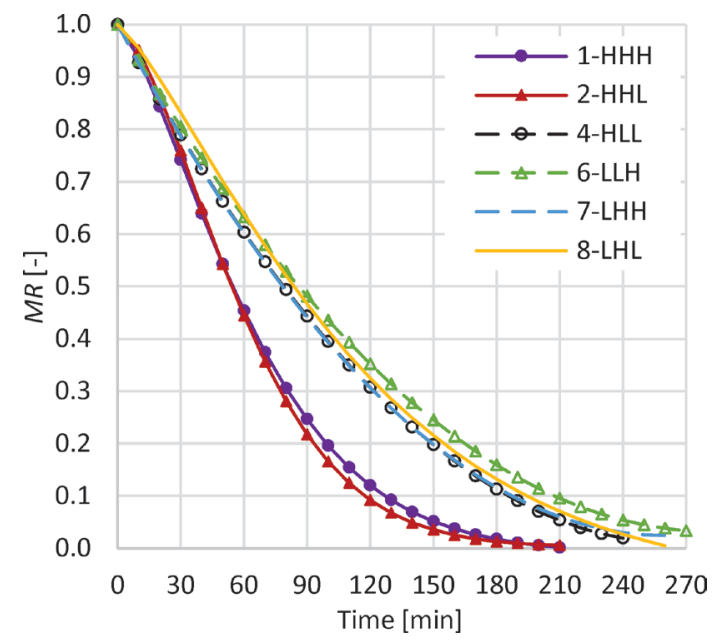

Fig. 6. Modeled moisture ratio for all operating conditions: solid lines/markers according to modified Nadhari model, dashed lines/ no-fill markers according to Wang Singh model

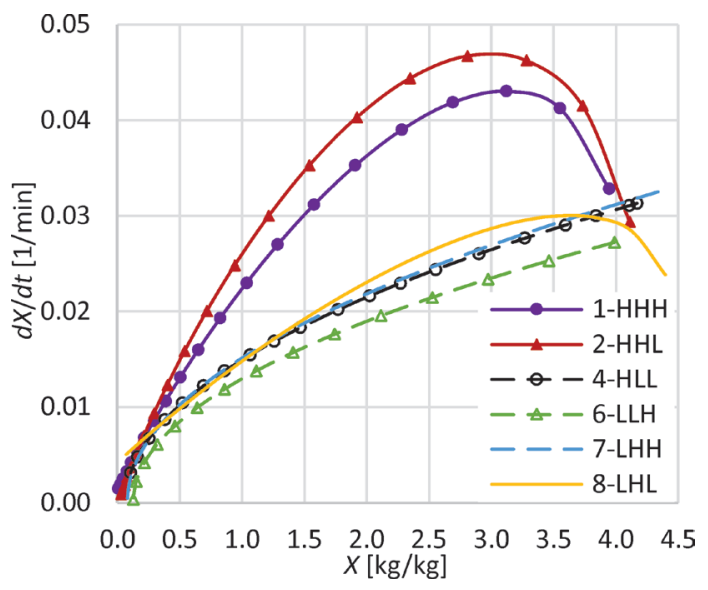

Fig. 7. Krischer curves for all operating conditions

\subsection{Layer Porosity and Drag Force}

The presented drying curves enable basic qualitative assessment of relations between operating parameters and drying curves, but do not provide enough data for modeling of these relations. Furthermore, some uncertainty can be observed in the results which causes some of the drying curves to deviate from expectations. The unexpected variation of results could in large be attributed to non-controlled experiment parameters, where the sludge layer properties were identified as the most significant. The sludge layer was formed by loading pre-formed sludge extrudates on the drying grate by hand. Despite effort to produce sludge layers with consistent properties for all tests, there was inevitable variation of layer structure from test to test. In some cases, the extrudates were more easily deformed and formed aggregates that could not be manually separated while in some cases the extrudates were more stable and formed a more consistent porous layer. Consequent variation in layer structure and homogeneity could result in different courses of layer shrinkage and cracking, thus different evolution of layer porosity, air flow distribution and drying rate on a local scale.

Current analysis could not be performed by considering local anomalies, but rather focused on measured integral (space-averaged) parameters. The most important integral layer properties that varied from test to test were identified to be its mass, initial moisture content and porosity. All these parameters were measured either directly (mass, initial moisture) or indirectly (porosity). Variation of porosity during drying was assessed by examining variation of pressure drop across the layer and the associated drag force. The two parameters were falling continuously during drying, as indicated in Figs. 2 and 3 for operating condition 8-LHL. The layer porosity was increasing with time due to shrinkage and cracking of the material. This phenomena is of great importance for the presented through-flow convective drying setup as it can significantly affect the contact area and the heat and mass transfer rates between the drying air and the dried material. Current results allow identification and qualitative assessment of the effects of variable porosity on drying, whereas a more detailed experimental treatment and analysis is foreseen in further studies.

Fig. 8 presents drag force as a function of time for two operating conditions that have the most weighed data and therefore the best defined drying curves. The operating condition 4-HLL actually developed the highest drag force of all the tests whereas the operating 
condition 8-LHL was in this respect a typical test at low air velocity. The measured data, represented by markers in Fig. 8, was fitted by a model that was determined by using the curve fitting tool ZunZun [39], which provides fitting of data with a wide range of functions and selection of best function according to the selected statistical criteria. In the presented case the best function was limited to 3-parameter equations and was defined as the function with the lowest $R M S E$ value. The resulting model in form of Eq. (7) provided an excellent fit to data for the two measured operating conditions, as evident from the $R^{2}$ values in Table 5.

$$
F_{d}=a \cdot t^{b t}+c .
$$

The model parameters are clearly reflected in the curve shape: $a+c$ represents the initial value (at $t=0$ ), $b$ represents the curve gradient and $c$ represents the final value (at $t=$ inf.). The fitted parameter values are given in Table 5.

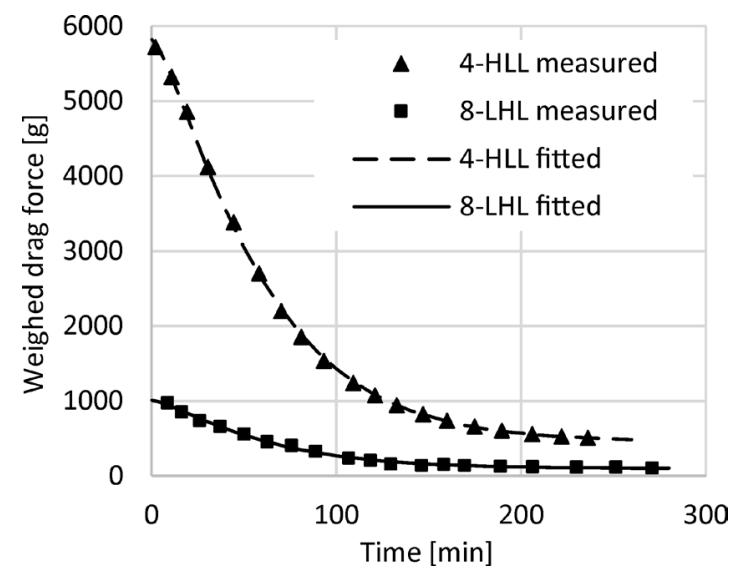

Fig. 8. Weighed and modeled drag force for operating conditions 4-HLL and 8-LHL

Table 5. Drag force model parameters

\begin{tabular}{lcccc}
\hline & $a$ & $b$ & $c$ & $R^{2}$ \\
\hline 4-HLL & 5351 & -0.00372 & 464 & 0.9997 \\
\hline 8-LHL & 908 & -0.00366 & 102 & 0.9963 \\
\hline
\end{tabular}

The decreasing of drag force (or pressure drop through layer) during the course of drying could be associated with increasing of air flow rate. However, since changes in layer pressure drop had a minor effect on the fan performance, as explained in section Experimental setup, the increase in flow rate (or average air velocity) during drying was calculated to be maximum $3.5 \%$.

\subsection{Total Drying Time}

In industrial sludge drying applications, it is typically required to remove most of water from the sludge, therefore modeling of total drying time under different drying air conditions was performed. For this purpose, the end of drying was defined to occur once the 3-minute averaged sludge mass gradient reached 0.5 $\mathrm{g} / \mathrm{min}$. In this instance, all drying curves practically leveled off and the sludge moisture ratios reached values of around 0.01 . The selected definition of total drying time enabled evaluation of two additional tests (3-HLH, 5-LLL) that were not included in the preceding analysis due to insufficient data for full definition of their drying curves. Therefore, 8 operating conditions in total were available for the drying time modeling by the multiple regression analysis. The measured drying time data was fitted to the exponential and linear models by trying several combinations of independent variables and finally the exponential model was selected since it provided a better fit to data. The exponential model with $n$ independent variables $(x)$ and one dependent variable $(y)$ is in general written as:

$$
y=\beta_{0} \prod_{i=1}^{n} x_{i}^{\beta_{i}} .
$$

The most influential variables that defined the total drying time were identified to be the initial sludge mass $\left(m_{s}\right)$, the initial sludge moisture content or dry matter $(D M)$, the drying air temperature $(T)$ and velocity $(v)$. Since influence of the initial sludge mass on the drying time was almost linear it was decided to define the drying time as specific time per mass of sludge, $t_{m}=t / m_{s}[\mathrm{~min} / \mathrm{kg}]$. By considering air velocity in $\mathrm{m} / \mathrm{s}$, air temperature in ${ }^{\circ} \mathrm{C}$ and dry matter in $\mathrm{wt} \%$ and fitting coefficients according to the least squares method the following model was obtained:

$$
t_{m}=1043 v^{-0.528} T^{-1.122} D M^{-0.988} .
$$

Coefficient of determination $\left(R^{2}\right)$ for the model is 0.944 . Plot of modeled vs. measured total drying time (Fig. 9) shows that the model adequately predicts the drying time within the investigated range of drying conditions. Exponents in the model are all negative which reflects negative correlation between the drying time and the drying air velocity and temperature and the initial sludge dry matter. Interestingly, the exponents values are very close to values of -0.5 and -1.0 . By rounding the exponents to the mentioned values and adjusting the leading constant a simplified model is obtained: 


$$
t_{m}=617 v^{-0.5} T^{-1} D M^{-1}=\frac{617}{\sqrt{v} T D M} .
$$

Coefficient of determination $\left(R^{2}\right)$ for the above model is 0.935 , which is comparable to the initial model (Eq. (9)). However, due to its mathematical simplicity, the Eq. (10) provides a clearer representation of relations between the involved variables. Similarities between the model and the physical laws, related to drying and flows through porous media, could not be determined. The coincidental simplicity of the model is linked to the selected system of units. This is especially evident in case of temperature, where changing units from degrees Celsius to Kelvin causes the exponent for temperature to take value far from -1.0 .

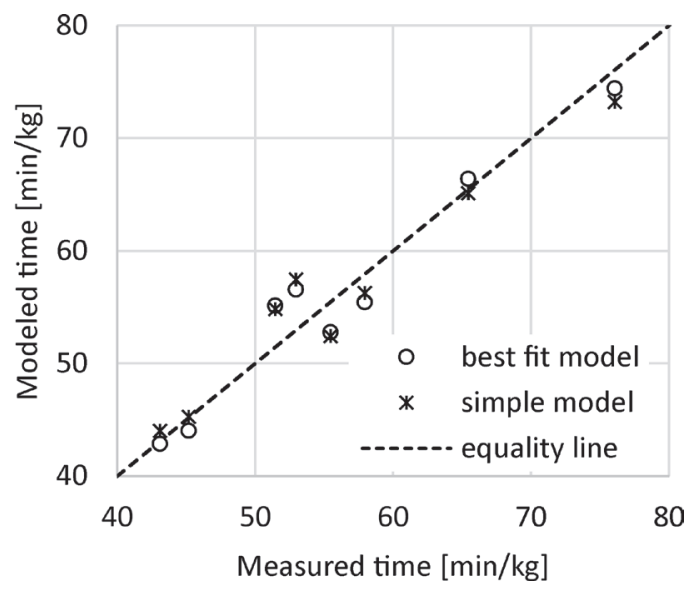

Fig. 9. Modeled vs. measured specific drying time

As evident from Fig. 9, two points are located above the line of equality with a slightly higher deviation compared to other points. These two points correspond to tests 4-HLL and 8-LHL, which were reference tests with the most frequent sludge weighing. Incidentally, these two tests also developed higher initial drag forces compared to other tests. These specifics could act as accelerators of drying, since the total drying time in these two tests was actually shorter than predicted by the model. Definition of relations between the drag force (or pressure drop) and drying parameters was not possible based on current experimental data, therefore further experimental work and analysis is planned to investigate these effects in more detail.

\section{CONCLUSIONS}

The sewage sludge drying experiments were conducted by forming the sludge sample as a porous layer and blowing the drying air in through-flow. Weighing of the sludge sample during drying was affected by the drag force, caused by passing of the air through the layer. The drag force variability between the tests was significant and was a function of sludge layer characteristics that could not be fully controlled. Nevertheless, the changing of drag force over time was modeled by a simple monotonic decreasing function that showed excellent agreement to the selected measured data. The sludge layer drying kinetics was determined by fitting the measured data to the most common drying models. Based on statistical criteria it was not possible to determine a single model, instead, two models, the modified Nadhari and the Wang Singh model, were determined as most suitable. The total drying time per kilogram of sludge was modeled as a function of the drying air temperature, the drying air velocity and the initial sludge dry matter content. Total drying times between 43 minutes and 76 minutes per kilogram of sludge were obtained for the investigated range of drying air conditions.

The presented experiments were representative of the conditions in belt dryers, where sludge is dried in layers in through-flow. The results demonstrated the importance of time-dependent sludge layer characteristics, most specifically its porosity, that is reflected in the pressure drop through the layer and consequently the drag force. However, exact relations between the drying air parameters, the layer porosity and the drying kinetics could not be defined considering current data. Further experiments with upgraded measurement systems will be conducted in order to analyze changes of layer structure over time due to shrinkage and cracking and to relate these effects to the drying process.

\section{ACKNOWLEDGEMENTS}

The authors acknowledge the financial support from the Slovenian Research Agency (research core Funding No. P2-0401).

\section{REFERENCES}

[1] Fytili, D., Zabaniotou, A. (2008). Utilization of sewage sludge in EU application of old and new methods-A review. Renewable and Sustainable Energy Reviews, vol. 12, no. 1, p. 116-140, D0l:10.1016/j.rser.2006.05.014.

[2] Yang, F., Chen, J., Yang, M., Wang, X., Sun, Y., Xu, Y., Qian, G. (2019). Phosphorus recovery from sewage sludge via incineration with chlorine-based additives. Waste Management, vol. 95, p. 644-651, D0l:10.1016/j. wasman.2019.06.029. 
[3] Donatello, S., Tong, D., Cheeseman, C. R. (2010). Production of technical grade phosphoric acid from incinerator sewage sludge ash (ISSA). Waste Management, vol. 30, nos. 8-9, p. 1634-1642, DOI:10.1016/J.wasman.2010.04.009.

[4] Bennamoun, L., Arlabosse, P., Léonard, A. (2013). Review on fundamental aspect of application of drying process to wastewater sludge. Renewable and Sustainable Energy Reviews, vol. 28, p. 29-43, D0I:10.1016/j.rser.2013.07.043.

[5] Bennamoun, L., Fraikin, L., Li, J., Léonard, A. (2016). Forced Convective Drying of Wastewater Sludge with the Presentation of Exergy Analysis of the Dryer. Chemical Engineering Communications, vol. 203, no. 7, p. 855-860, D0l:10.1080/0 0986445.2015.1114475.

[6] Léonard, A., Blacher, S., Marchot, P., Pirard, J. P., Crine, M. (2005). Convective drying of wastewater sludges: Influence of air temperature, superficial velocity, and humidity on the kinetics. Drying Technology, vol. 23, no. 8, p. 1667-1679, DOI:10.1081/DRT-200065082.

[7] Léonard, A., Vandevenne, P., Salmon, T., Marchot, P., Crine, M. (2004). Wastewater sludge convective drying: Influence of sludge origin. Environmental Technology, vol. 25, no. 9, p. 1051-1057, D0I:10.1080/09593330.2004.9619398.

[8] Tao, T., Peng, X. F., Lee, D. J. (2005). Structure of crack in thermally dried sludge cake. Drying Technology, vol. 23, no. 7, p. 1555-1568, Dol:10.1081/DRT-200063547.

[9] Font, R., Gomez-Rico, M. F., Fullana, A. (2011). Skin effect in the heat and mass transfer model for sewage sludge drying. Separation and Purification Technology, vol. 77, no. 1, p. 146161, D0I:10.1016/j.seppur.2010.12.001.

[10] Bennamoun, L., Fraikin, L., Léonard, A. (2014). Modeling and simulation of heat and mass transfer during convective drying of wastewater sludge with introduction of shrinkage phenomena. Drying Technology, vol. 32, no. 1, p. 13-22, DOI:10.1080/07373937.2013.807281.

[11] Leonard, A., Blacher, S., Marchot, P., Crine, M. (2002). Use of X-ray microtomography to follow the convective heat drying of wastewater sludges. Drying Technology, vol. 20, nos. 4-5, p. 1053-1069, D0I:10.1081/DRT-120004013.

[12] Fraikin, L., Herbreteau, B., Salmon, T., Nicol, F., Crine, M., Léonard, A. (2015). Use of an experimental design to characterize the convective drying behavior of different sludges. Drying Technology, vol. 33, no. 11, p. 1302-1308, DOI:10.1080/07373937.2015.1026979.

[13] Kobayashi, N., Okada, K., Tachibana, Y., Kamiya, K., Ito, T., Ooki, H., Zhang, B., Suami, A., Itaya, Y. (2020). Drying behavior of sludge with drying accelerator. Drying Technology, vol. 38, nos. 1-2, p. 38-47, Dol:10.1080/07373937.2019.1605611.

[14] Tao, T., Peng, X. F., Lee, D. J. (2005). Thermal drying of wastewater sludge: Change in drying area owing to volume shrinkage and crack development. Drying Technology, vol. 23, no. 3, p. 669-682, D0I:10.1081/DRT-200054164.

[15] Danish, M., Jing, H., Pin, Z., Ziyang, L., Pansheng, Q. (2016). A new drying kinetic model for sewage sludge drying in presence of $\mathrm{CaO}$ and $\mathrm{NaClO}$. Applied Thermal Engineering, vol. 106, no. 2016, p. 141-152, D0l:10.1016/j. applthermaleng.2016.05.191.

[16] Léonard, A., Meneses, E., Le Trong, E., Salmon, T., Marchot, P., Toye, D., Crine, M. (2008). Influence of back mixing on the convective drying of residual sludges in a fixed bed. Water Research, vol. 42, nos. 10-11, p. 2671-2677, D0l:10.1016/j. watres.2008.01.020.

[17] Li, J., Plougonven, E., Fraikin, L., Salmon, T., Toye, D., Nistajakis, E., Léonard, A. (2017). Influence of sawdust addition on drying of wastewater sludges: Comparison of structural characteristics. Drying Technology, vol. 35, no. 8, p. 925-932, D0I:10.1080/07373937.2016.1253020.

[18] Li, J., Fraikin, L., Salmon, T., Bennamoun, L., Toye, D., Schreinemachers, R., Léonard, A. (2015). Investigation on convective drying of mixtures of sewage sludge and sawdust in a fixed bed. Drying Technology, vol. 33, no. 6, p. 704-712, DOI:10.1080/07373937.2014.982254.

[19] Li, J., Bennamoun, L., Fraikin, L., Salmon, T., Toye, D., Schreinemachers, R., Léonard, A. (2014). Analysis of the shrinkage effect on mass transfer during convective drying of sawdust/sludge mixtures. Drying Technology, vol. 32, no. 14, p. 1706-1717, D0I:10.1080/07373937.2014.924136.

[20] Li, J., Fraikin, L., Salmon, T., Plougonven, E., Toye, D., Léonard, A. (2016). Convective drying behavior of sawdust-sludge mixtures in a fixed bed. Drying Technology, vol. 34, no. 4, p. 395-402, D0I:10.1080/07373937.2015.1076835.

[21] Bennamoun, L., Crine, M., Léonard, A. (2013). Convective drying of wastewater sludge: Introduction of shrinkage effect in mathematical modeling. Drying Technology, vol. 31, no. 6, p. 643-654, D0I:10.1080/07373937.2012.752743.

[22] Li, J., Wu, C. W., Fraikin, L., Salmon, T., Toye, D., Nistajakis, E., Léonard, A. (2019). Convective drying of sawdust-sludge mixtures: The effect of the sludge matrix. Drying Technology, vol. 37, no. 7, p. 920-927, Dol:10.1080/07373937.2018.14 80027.

[23] Lijuan, Z., Junhong, Y., Shanshan, W., Zhonghua, W. (2019). CO-drying characteristics of sticky sewage sludge preconditioned with biomass and coal. Drying Technology, vol. 37, p. 1-11, D0l:10.1080/07373937.2019.1692861.

[24] Zhang, X. Y., Chen, M. Q., Huang, Y. W., Xue, F. (2016). Isothermal hot air drying behavior of municipal sewage sludge briquettes coupled with lignite additive. Fuel, vol. 171, p. 108115, D0I:10.1016/j.fuel.2015.12.052.

[25] ISO 5167:2003. Measurement of fluid flow by means of pressure differential devices inserted in circular-cross section conduits running full: Orifice Plates. International Organization for Standardization, Geneva.

[26] Midilli, A., Kucuk, H., Yapar, Z. (2002). A new model for singlelayer drying. Drying Technology, vol. 20, no. 7, p. 1503-1513, DOl:10.1081/DRT-120005864.

[27] Kucuk, H., Midilli, A., Kilic, A., Dincer, I. (2014). A Review on thin-layer drying-curve equations. Drying Technology, vol. 32, no. 7, p. 757-773, DOI:10.1080/07373937.2013.873047.

[28] Zhang, X. Y., Chen, M. Q. (2016). A comparison of isothermal with nonisothermal drying kinetics of municipal sewage sludge. Journal of Thermal Analysis and Calorimetry, vol. 123, no. 1, p. 665-673, D0l:10.1007/s10973-015-4933-1.

[29] Reyes, A., Eckholt, M., Troncoso, F., Efremov, G. (2004). Drying kinetics of sludge from a wastewater treatment plant. Drying Technology, vol. 22, no. 9, p. 2135-2150, D0I:10.1081/DRT200034218 
[30] Celma, A. R., Cuadros, F., López-Rodríguez, F. (2012). Convective drying characteristics of sludge from treatment plants in tomato processing industries. Food and Bioproducts Processing, vol. 90, no. 2, p. 224-234, D0l:10.1016/j. fbp.2011.04.003.

[31] Zhou, J., Zhang, R., Wang, X., Chen, S., Luo, A., Niu, D., Chai, X., Zhao, Y. (2017). NaHCO3-enhanced sewage sludge thin-layer drying: Drying characteristics and kinetics. Drying Technology, vol. 35, no. 10, p. 1276-1287, D0l:10.1080/07373937.2016. 1249878.

[32] Bruce, D. M. (1985). Exposed-layer barley drying: Three models fitted to new data up to $150^{\circ} \mathrm{C}$. Journal of Agricultural Engineering Research, vol. 32, no. 4, p. 337-348, Dol:10.1016/0021-8634(85)90098-8.

[33] Page, G.E. (1949). Factors Influencing the Maximum Rates of Air Drying Shelled Corn in Thin Layers. MSc thesis, Purdue University, West Lafayette.

[34] Wang, C. Y., Singh, R. P. (1978). A single layer drying equation for rough rice, ASAE Paper, No. 78-3001.
[35] Togrul, I. T., Pehlivan, D. (2002). Mathematical modelling of solar drying of apricots in thin layers. Journal of Food Engineering, vol. 55, no. 3, p. 209-216, D0I:10.1016/S02608774(02)00065-1.

[36] Henderson, S.M. (1974). Progress in developing the thin layer drying equation. Transactions of the ASAE, vol. 17, no. 6, p. 1167-1168, Dol:10.13031/2013.37052.

[37] Nadhari, W. N. A. W., Hashim, R., Sulaiman, O., Jumhuri, N. (2014). Drying kinetics of oil palm trunk waste in control atmosphere and open air convection drying. International Journal of Heat and Mass Transfer, vol. 68, p. 14-20, DOl:10.1016/j.jheatmasstransfer.2013.09.009.

[38] Ertekin, C., Firat, M. Z. (2017). A comprehensive review of thin-layer drying models used in agricultural products. Critical Reviews in Food Science and Nutrition, vol. 57, no. 4, p. 701717, D0I:10.1080/10408398.2014.910493.

[39] Philips, J. R. Zunzun, from http://zunzun.com, accessed on 2019-01-22. 